\title{
The cosmos and its contents
}

\section{David W. Hughes}

NEW BOOKS on astronomy continue to flood on to the market, the fact that we are not swamped by them being due to their short life; few last more than two years before going out of print or finding their way onto the remainder shelves. The astronomical second edition is indeed a rarity. Nineteen eighty-two, however, does have advantage over other years - it is the twenty-fifth anniversary of the start of the space race. My first book deals with just that.

Sputnik to Space Shuttle by Iain Nicolson (Sidgwick and Jackson, £7.95) chronicles the childhood of the space age. We start with the characteristic "bleep bleep" of the Soviet Union's Sputnik 1 which astonished the world on 4 October 1957 and end with the graceful landing of Columbia which completed the fourth test of the Space Shuttle in June of this year. Between these dates there is all the excitement of the race into space, the Soviet Union and the United States continually jockeying for the lead. First dog in space, man in space, woman in space and space walk went to the USSR; first voice from space, navigation satellite, meteorological satellite and communications satellite went to the USA; first photographs of the far side of the Moon, first lunar soft-landing, first Venus softlanding to the USSR; first men on the Moon, first two-planet mission, first Mars lander to the USA. One could continue but why not just read Nicolson's book. He is a lively writer with a clear, easily readable style and his book is an excellent review of our 25 years "out there".

For a more scientific bias we have Planets of Rock and Ice by Clark R. Chapman (Charles Scribner's Sons, \$13.95), a revised and expanded edition of his 1977 book The Inner Planets. The author folds together our knowledge of terrestrial planets with the new-found information gleaned from the space probe observations of the satellites and rings of Saturn and Jupiter. This book is raised above the mundane plane of the usual account of the planets by the many anecdotal insights into the workings of the mind of a planetologist that grace its pages. Chapman loves his job, loves the planets and it shows.

In the book he inveighs against the shut down of Solar System explorations that has been inflicted on the American scientific community. There is, however, a very minor advantage to this in that scientists will no longer be distracted by the "gee whiz" findings of new planetary encounters or the need to plan for forthcoming missions. So the storerooms of accumulated information, the thousands of pictures and unprocessed magnetic reels of data, now have a chance of being sifted and scrutinized. Be this as it may, there are still a multitude of places to go to and experiments that cry out to be performed.

The evolution of Earth's surface and atmosphere and the way it contrasts with its rocky neighbours is obviously of great interest and concern to Chapman. His ability to express this vividly makes the book a joy to read. But how different is the state of planetology today in comparison to the time when Apollo 11 landed. The London bookmakers William Hill were then offering odds of 100:1 against a manned Mars landing before 20 July 1976 and "evens" on a landing before $20 \mathrm{July}$ 1979 !

The Planet Venus by Garry E. Hunt and Patrick Moore (Faber \& Faber/Faber Inc.; $£ 10, \$ 22)$ divides neatly into two parts. Venus before the space age is mainly written by Patrick Moore and concentrates on the way Earth-based telescopic and spectrographic observations moulded our pre-1962 view of the planet. Transits, the Black Drop problem and the ashen light are carefully reviewed, as are more marginal and esoteric phenomena such as the debate that took place in the 1950 s as to whether the surface was covered with oil, water or dust, the aphroditographic work of Percival Lowell that "revealed" a series of dark patches and strips on the planet and a rotation period synchronous with the orbital period, the discovery of a phantom satellite and its subsequent demise, and the early attempts at measuring the surface temperature.

Venus made its entry into our space age in December 1962 when Mariner 2 flew by, and the voyages of discovery have continued with a whole series of Venera, Mariner and Pioneer spacecraft. Garry Hunt reviews the latest ideas about Cytherean greenhouse effects, atmospheric sulphur cycles, wind profiles, circulation patterns, and day and night variations. Pictures are shown of the surface of Venus near the Venera 9,10 and 13 spacecraft, and the results of the radar observations of the landscape using data from the Pioneer orbiter and the Arecibo and Goldstone radar facilities are reviewed.

Venus is often regarded as the Earth's twin but an identical twin it certainly is not. This book is a very good account of our knowledge of our nearest planetary neighbour; I was especially impressed by the extensive reference section which will encourage readers to delve further.

Now for something completely different. What started in the United Kingdom in 1767 and the United States in 1855? It was the forerunners of the Astronomical Almanac and the 1983 version (US Government Printing Office/ HMSO; \$16, £9.25) would make an excellent gift for the astronomer who has nearly everything. Where else would you easily find the universal times of the greatest northern elongation of the satellite of Pluto close by lists of the 194 brightest galaxies (together with diameters, photometric data and velocities), the 1,482 stars brighter than $4.5^{\mathrm{m}}$, the latitude and longitude of the world's optical observatories, the circumstances of all the 1983 eclipses, together with a host of all the usual things we refer to the almanac for? Many happy hours can be spent dipping into this book.

To move closer to the stars, The Astronomy Handbook by James Muirden (Kingfisher/Archon; £3.95, \$8.95) is a colourful, profusely illustrated guide to the constellations, Sun and Solar System. It is aimed at the teenage astronomer. Muirden concentrates on the practical side of the subject and I really like his plan for a do-ityourself planetarium - no young astronomer's bedroom should be without one. The book is full of encouragement, more than enough to make any youngster grab a pair of binoculars, brave the cold of a starry night and take to examining the heavens.

Planets first, stars next and finally the Universe and all the theories and phenomena of the cosmos. Deep Space by Colin Ronan (Macmillan, London/Macmillan, New York; $£ 10.95, \$ 25.95$ ) and The Restless Universe by Nigel Henbest and Heather Couper (George Philip, f8.95) both throw their net wide and try and sweep in the whole zoo of astronomical objects from pulsars, quasars and black holes down to stars and planets. Both delve into the mysteries of the big bang, the search for alien life, how it will end (the big crunch?), and the birth and death of stars. It is the differences between the two books that are really startling. Ronan's book is a visual treat and is profusely illustrated not only with photographs of celestial objects but also with a host of well-conceived figures: for example, one diagram shows the relative positions of the brightest members of the Local Group of galaxies and with the accompanying table can form the basis of a model; another does the same for the Sun's nearest 24 stellar neighbours. It is very hard to resist making these models. I gave in straightaway and had great fun. Time and again the illustrations really punch home the message of the text. The figures are exciting, the text interesting and I have no hesitation in recommending Ronan's book.

Henbest and Couper confine themselves to 24 figures and 24 colour photographs and I feel that the authors have set themselves the age-old problem of describing a spiral staircase with their hands in their pockets. This comment apart it must be admitted that the text rattles along at a heady pace - nobody will fall asleep reading this book.

David W. Hughes is a Lecturer in Astronomy and Physics at the University of Sheffield. 